thinly. The authors have made a good attempt at condensing our theoretical ideas, but havo left tho reader undecided regarding application of the theories. The problems of maximum flux and of burn-out have been of vital consideration in the development of nuclear reactors, but neither these nor the question of high fluxes obtained with rockets and sub-cooled boiling are given much coverage.

Chapter 4 eovers the less well analysed field of radiation and will undoubtedly prove of real value to all concerned in work at high temperatures and with furnaces. There is plenty of material here for the thinker, and the chapter well deserves study. Our knowledge of the problems of the drying of solids is still sketchy, and Dr. Nissen and Mr. Macmurray have given a useful summary of the position, but the growing importance of spray drying and the use of fluidized bed dryers are not sufficiently outlined. There is a little duplication here of the principles of heat transfer which are discussed in the first chapter, but with a wide range of authors this may be helpful. A good account is given of the drying of paper on a series of cylinders and this provides an excellent indication of the difficulty in applying theoretical expressions to practical problems. Some good drawings of industrial drying plant would have given the reader a clearer picture of the engineering nature of the units, and a discussion of the cost of drying by various methods should have been included to give the practical ongineer a guide to the economics of the operation.

The final chapter, on heating and ventilation, is a welcome addition, which has not been included in the chemical engineering field to any great extent in the past.

This book contains a very useful summary of our present knowledge on the basic principles of heat transfer, but it would have been pleasant to roport that there were a large number of worked illustrations from practice. These would embody the kind of information which is lacking in literature to-day, and, although it is clearly difficult to be precise, some real attempt to bring home the difficulties of practice might well have been attempted.

The design engineer is eager for illustrations of the right method for use of techniques, and the more abstract the mathematical methods, as with those on unsteady state processes in Chapter 1, the greater the need for confirmation, by examplo, that these methods are not only reasonably accurato, but well worth while if better plants are to bo designed.

J. M. CoulsoN

\section{VACUUM FOR THE TECHNICIAN}

\section{Vacuum Technology}

By Prof. Andrew Guthrie. Pp. xii +532. (New York and London: John Wiley and Sons, Inc., 1963.) 94s.

INTENDED primarily for the technician, this useful 1 book covers most aspects of vacuum technology excluding applications. Very little background knowledge is assumed of the reader; the text is illustrated by good line-diagrams and photographs and is lucidly written, though the author does exhibit occasionally the disconcerting habit of writing very long paragraphs containing unexpected changes in ideas.

Attractive features of this volume are the many worked examples, the carefully selected tabulated data, the repeated emphasis on experimental procedure and correct operation of plant and the useful chapters entitled "Cleaning Techniques" and "Some Fabrication Techniques".

The text is reliable and with a welcome correct use of terminology. However, some controversial points and errors worth mentioning with the view of being helpful and also indicating the treatment adopted are the following. On p. 42 appears the statement, "If it wore possible to connect the inlet of a pump directly to the vacuum vessel then pumping speeds at the vessel would be given directly by the speed curve of the pump. In practice, this is not possible, simply due to space considerations". In fact, this direct connexion is practised, as, for example, in connecting an oil diffusion pump to the base-plate of a vacuum coating chamber. Admittedly here an isolation baffle valve is generally desirable between the pump and the chamber and this will reduce the speed, but it is not "space considerations" which are the difficulty. In some cases, for example, the widely used equations $(2 \cdot 8)$ and $(3 \cdot 2)$, a formula is given without proof, which is undesirable where the deduction is simple, especially in view of the author's commendable emphasis on an understanding of elementary kinetic theory in the early chapters. Occasionally, the author's clarity of exposition deserts him, as in Fig. 3.2, where the operation of gasballast would not be understood in relation to the accompanying text. Errors occur on p. 53, where division by 28.3 becomes equivalent to multiplication by 0.353 , in the statement of Example 1 on p. 63 and in the instructions about cutting off the heater on p. 105. The operation of the Becker molecular pump is not clear from the diagrams and description, and the use of a modulator electrode in the Redhead version of the Bayard-Alpert gauge is not explained. It is surprising to see emphasis given to the X-ray limitation of the Bayard-Alpert gauge without it being stressed in describing the conventional hot-cathode ionization gauge. It is difficult, in view of the problems of temperature measurement and inadequate knowledge of accommodation coefficients, to make the Knudsen gauge an absolute instrument as is implied on p. 187.

In many respects this book cen be strongly recommended for the technician, and the scientist or qualified technologist will find much useful information in it. The text could have been made shorter by omitting such data as explanations of decimals, simple index notation, logarithms, rather elaborated numerical work in answer to examples and simple physics amply detailed in British text-books for the Ordinary Level of the General Certificate of Education. A shorter text would also have been beneficial in reducing the rather high price.

\section{J. YARWOOD}

\section{HOW CLOTTING BEGINS}

The Contact Phase of Blood Coagulation

By H. L. Nossel. Pp. xv +160 . (Oxford: Blackwell Scientific Publications, 1964.) 35s.

INTIL recently the investigation of the biochemistry of blood coagulation has depended almost entirely on measuring the time between an experimental manipulation and the appearance of the fibrin clot, together with great ingenuity in varying the manipulation. Thus, in The Contact Phase of Blood Coagulation, Dr. Nossel writes (p. 2): "The occurrence of the fibrin clot is the only stage of the clotting process which can be directly observed. All knowledge of preceding stages has been inferred from changes in the rate of fibrin formation". Dr. Macfarlane has recently suggested (Nature, 202, 498; 1964) that the existence of a long series of reactions leading to blood clotting has a biological purpose, by acting as a biochemical amplifier system. If this is so, it implies that, the earlier a reaction in the sequence, the smaller the amount of chemical change that occurs in it. Progress in coagulation research will, presumably, largely depend on establishing the biochemical nature of the earlier reactions and on making them measurable.

This book describes experiments in which, as usual, the indicator of what is happening is the clotting time. However, Dr. Nossel has used great ingenuity to contribute to our knowledgo of the earliest stage of clotting, 